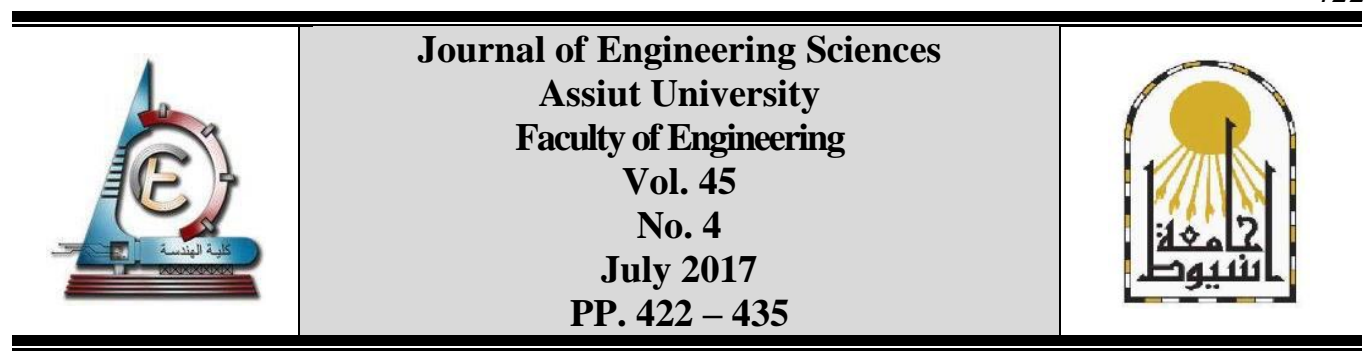

\title{
FLEXURAL BEHAVIOR OF SELF-COMPACTING CONCRETE PRISMS REINFORCED WITH GEOGRIDS
}

\author{
Mostafa Abd-Elmohsen \\ Construction Research Institute, NWRC, Delta-Barrage 13621, Egypt.
}

Received 18 April 2017; Accepted 25 May 2017

\begin{abstract}
The aim of this study is to investigate experimentally the flexural behavior of self-compacting concrete prisms reinforced with geogrids. Furthermore, assessing the feasibility of utilizing geogrids in members that are exposed to low levels of tensile stresses needs to be carried out. Therefore, three different geogrid types were utilized in reinforcing concrete prisms. For each geogrid type, one, two and three layers were employed. Experimental results confirm the benefits of utilizing geogrids as tensile reinforcement evident from its flexural behavior. This behavior was described in terms of load-deflection, flexure strength, post peak response and absorbed energy. It was found that employing geogrids as reinforcement significantly improves the post peak behavior and changes the mode of failure from brittle to ductile one. However, a debonding failure was monitored for all geogrid prisms due to the smooth surface of geogrids. This result elaborates the urgent need to enhance the bond between geogrids and concrete, which is certainly supposed to improve the overall flexural behavior of prisms as have been verified in this study.
\end{abstract}

Keywords: Self-compacting concrete; Flexural behavior; Load-deflection; Absorbed energy; Geogrids; Reinforcement; Geosynthetics.

\section{Introduction}

Geogrid is a geosynthetic material consisting of parallel arrangements of connected tensile ribs with openings of adequate size to permit strike-through of surrounding geotechnical material [11]. Commercial geogrid products are classified into four types; extruded geogrids, woven geogrids, welded geogrids, and geogrid composites. Extruded geogrids are fabricated from polymer sheets by punching and stretching them in either one or two directions for improvement of engineering properties. Woven geogrids are fabricated by weaving polymer fibers, typically polypropylene or polyester, which can be coated to increase its abrasion resistance [5]. Welded geogrids are fabricated by welding the junctions of woven segments of extruded polymers. Geogrid composites are geogrids that are joined with other products forming a composite system capable of performing a specific application. Extruded geogrids have indicated good behavior for reinforcement of pavement applications when compared to the other types [7, 14, 18]. Extruded geogrids can be categorized into two types according to the direction of stretching throughout their fabrication, uniaxial and biaxial. Uniaxial geogrids are produced by stretching a regularly punched polymer sheet in the longitudinal direction, and therefore the longitudinal 
Mostafa Abd-Elmohsen, Flexural behavior of self-compacting concrete prisms reinforced .........

direction retains a higher tensile strength than the transverse direction. Biaxial geogrids are produced by stretching a regularly punched polymer sheet in longitudinal and transverse directions at same time, and therefore the tensile strength is equal in both directions.

Geosynthetics have widely been used in geotechnical applications. They are utilized as reinforcement elements to achieve stabilization of soil [13]. Geogrids have been effectively utilized to enhance soft subgrades and provide a construction platform over them [7, 16]. In this application, geogrid improved the compaction ability of the overlying aggregates, and decreasing the required amount of replacing material. Numerous studies have also reported that utilizing geogrids in pavement layers extended their service life compared to similar sections without geogrids $[1,4,7,8,14,15,18]$.

A few researches have been performed on thin concrete members and overlays in pavements where steel reinforcement could not be placed due to durability and construction limitations [17]. These limitations include constraints and difficulties of placing steel reinforcement bars in thin sections, such as architectural elements, concrete overlays, and ultra thin white-toppings, furthermore the concerns of steel corrosion and extensive time for construction. Therefore, alternatives of replacing steel reinforcement bars, including the fiber reinforced polymer (FRP) composites have been extensively investigated as a viable alternative.

The objective of this study is to evaluate flexural behavior of Self-Compacting Concrete (SCC) prisms reinforced with different types of geogrids. The experimental program was conducted with 10 prisms. One was plain concrete left without reinforcement to be a datum and the other 9 prisms were reinforced with geogrids. The used geogrids were either uniaxial or biaxial geogrids. The geogrids were introduced in one, two or three layers. The prisms were subjected to flexural load and load-deflection response was observed.

\section{Experimental program}

\subsection{Material and mix proportioning}

Ordinary Portland Cement of CEM I $42.5 \mathrm{~N}$ was used. Gravel with a maximum nominal size of $15 \mathrm{~mm}$ and specific gravity of 2.51 was used as coarse aggregate. Natural sand with a fineness modulus of 2.32 and specific gravity of 2.63 was used as fine aggregate. Superplasticizer (SP) of high range water reducer without retarding was utilized to produce SCC with the desired fresh properties.

SCC mixture should exert high fluidity and segregation resistance ability in its fresh state. The target fresh properties for SCC mixtures were $600 \pm 20 \mathrm{~mm}$ for flow-ability, and $0.80 \pm 0.03$ for passing ability by adjusting the SP dose. SCC mixture was designed for a 28-day compressive strength of approximately $25 \mathrm{MPa}$. The proportions of SCC mixture are shown in Table (1).

Table 1.

Mixture Proportions of SCC

\begin{tabular}{|c|c|c|c|c|}
\hline $\begin{array}{c}\text { Cement } \\
\mathrm{kg} / \mathrm{m}^{3}\end{array}$ & $\begin{array}{c}\text { Water } \\
\mathrm{kg} / \mathrm{m}^{3}\end{array}$ & $\begin{array}{c}\text { Gravel } \\
\mathrm{kg} / \mathrm{m}^{3}\end{array}$ & $\begin{array}{c}\text { Sand } \\
\mathrm{kg} / \mathrm{m}^{3}\end{array}$ & $\begin{array}{c}\mathrm{SP} \\
\mathrm{kg} / \mathrm{m}^{3}\end{array}$ \\
\hline 400.00 & 176.00 & 893.90 & 893.90 & 5.20 \\
\hline
\end{tabular}




\section{Types of investigated geogrids}

Three different types of geogrids, one uniaxial and two types of biaxial, as shown in Fig.(1), were used as reinforcement layers for SCC prisms. Uniaxial geogrid (U-1) is manufactured from high density polyethylene sheet oriented in one direction. The first type of biaxial geogrid (BI-1) is extruded polypropylene geogrid. The second type of biaxial geogrid (BI-2) is a highly oriented polypropylene strap that is extruded and drawn. There are variations in the aperture geometry, dimensions and physical properties between the three types of geogrids. The ultimate tensile strength for each geogrid type was experimentally obtained using UTM machine and according to ASTM D6637 [2], Fig. (2). The physical and mechanical properties of each geogrid type are summarized in Table (2).

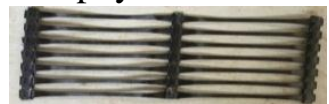

Uniaxial (U-1)

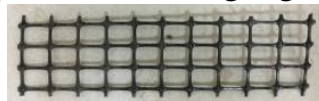

Biaxial (BI-1)

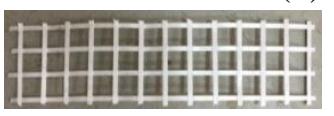

Biaxial (BI-2)

Fig. 1. Types of Geogrids

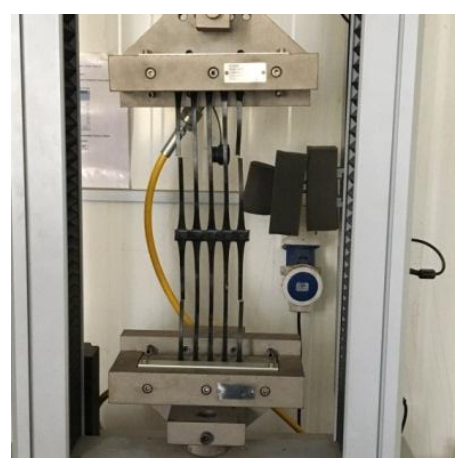

Fig. 2. Testing Geogrid Using Multi Rib Tensile Method

Table 2.

Physical and Mechanical Properties of Geogrids

\begin{tabular}{|l|c|c|c|}
\hline \multirow{2}{*}{ Properties } & \multicolumn{3}{|c|}{ Geogrid type } \\
\cline { 2 - 4 } & $\begin{array}{c}\text { Uniaxial } \\
(\mathrm{U}-1)\end{array}$ & $\begin{array}{c}\text { Biaxial } \\
(\mathrm{BI}-1)\end{array}$ & $\begin{array}{c}\text { Biaxial } \\
(\mathrm{BI}-2)\end{array}$ \\
\hline Material & polyethylene & polypropylene & polypropylene \\
\hline Unit weight, MD $\left(\mathrm{kg} / \mathrm{m}^{2}\right)$ & 0.87 & 0.48 & 0.25 \\
\hline Aperture size, MD $(\mathrm{mm})$ & 217 & 36 & 32 \\
\hline Aperture size, TD $(\mathrm{mm})$ & 16 & 34 & 32 \\
\hline Ultimate tensile strength, MD $(\mathrm{kN} / \mathrm{m})$ & 60.00 & 46.00 & 49.00 \\
\hline Strength at 2\% strain, MD $(\mathrm{kN} / \mathrm{m})$ & 18.00 & 15.00 & 16.00 \\
\hline Strength at 5\% strain, MD $(\mathrm{kN} / \mathrm{m})$ & 35.00 & 31.00 & 32 \\
\hline E $(\mathrm{kN} / \mathrm{m})$ & 5667 & 5333 & 5333 \\
\hline
\end{tabular}

Note: MD is the machine direction; TD is the transverse direction.

\section{Specimens}

Wooden moulds of inner dimensions $150 \times 150 \times 550 \mathrm{~mm}$ were used to fabricate prism specimens. First, the concrete was poured to a thick layer of $40 \mathrm{~mm}$. A theoretical concrete cover of $40 \mathrm{~mm}$ is chosen for the spreading simplicity as well as the applicability of geogrid layers to be well settled into concrete due to its formation and nature shown in Fig. (1). 
Mostafa Abd-Elmohsen, Flexural behavior of self-compacting concrete prisms reinforced ..........

Then, geogrid layers (one-layer, two-layers or three-layers) having dimensions of $150 \mathrm{x}$ $550 \mathrm{~mm}$ were put on the top of SCC layer, followed by pouring more SCC to completely fill the mould. The most advantage of using SCC is its consistency without compaction. Three prisms were prepared for each of the three geogrid type. These prisms were reinforced with one, two and three geogrid layers respectively. The total number of reinforced concrete prisms was 9. A plain concrete prism was prepared as a control specimen. Table (3) shows the configurations of the designed prisms.

Table 3.

List of Investigated Prisms

\begin{tabular}{|l|c|c|c|}
\hline \multirow{2}{*}{ Geogrid Type } & \multicolumn{3}{|c|}{ Prism Reinforcement } \\
\cline { 2 - 4 } & One layer & Two layer & Three layer \\
\hline Without geogrid & \multicolumn{3}{|c|}{ Plain concrete (PC) } \\
\hline Uniaxial & U-1-1 & U-1-2 & U-1-3 \\
\hline Biaxial-1 & BI-1-1 & BI-1-2 & BI-1-3 \\
\hline Biaxial-2 & BI-2-1 & BI-2-2 & BI-2-3 \\
\hline
\end{tabular}

\section{Testing setup and measurement procedure}

The 28 days average compressive strength of testing 3 standard cubes $(150 \times 150 \times 150$ $\mathrm{mm}$ ) for SCC mixture was $25.4 \mathrm{MPa}$, while the average indirect tensile strength (splitting strength) for 3 cylinders $(150 \mathrm{x} 300 \mathrm{~mm})$ was $2.20 \mathrm{MPa}$. The concrete prisms were subjected to flexural testing according to ASTM C 78 [3]. A universal testing machine was used to apply flexural loads on a simple prism with a configuration of third-point loading. Three vertical LVDTs were fixed on the prism to measure vertical displacement, Fig. (3). Two LVDTs were fixed on the upper surface of the prism just over the supports while the third was fixed on a plate fixed at mid height of the prism at mid-span. Both the machine load and the mid span displacement as the resultant of the measurements of the three LVDTs connected to a data logger were recorded. Fig. (4) shows a photo of specimen describing test setup with different measurement devices.

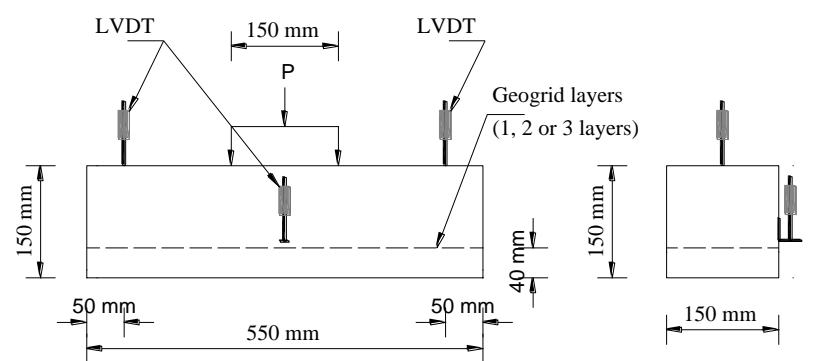

Fig. 3. Typical Section Showing Geogrid, Load, and LVDTs Locations 


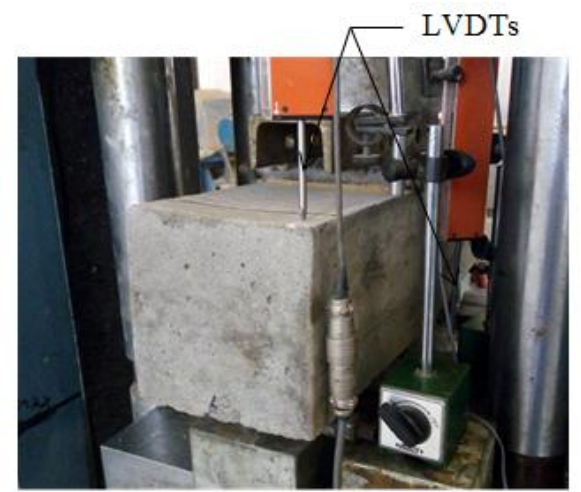

Fig. 4. Photo Describing Testing and Instrumentations Setup of Prisms

\section{Results and analysis}

\subsection{Load deflection behavior}

The load versus vertical mid span displacement (P- $\Delta$ ) curves, for the tested prisms with different configurations are shown in Figs. (5-8). As predicted, the PC prism failed suddenly in a brittle manner immediately after the maximum load was reached, Fig (5). This behavior is attributed to the brittle failure of concrete in the absence of reinforcement. For all reinforced prisms, concrete and geogrids absorbed the flexural tensile stress attributed to the bending action. The first crack is initiated at the bottom surface of the prisms once the flexural tensile strength of concrete is reached. After that, the tensile stress is completely transferred to the geogrids. This leads to a sudden drop in the load which is mainly attributed to the weak bond at geogrid-concrete interface as shown in the P- $\Delta$ curves, Figs. (6-8). The resistance to the applied load is increasing again due to the activation of geogrid tensile strength. The variation between flexure tensile stresses is mainly attributed to the crack propagation rate, which is probably due to the variation of the first crack location as well as cracks numbers within the middle third of the prism. Therefore, the load is redistributed through the bottom surface of the middle third of the prism and more cracks may appear especially, in case of biaxial geogrids. The cracks expand horizontally, leading to debonding, and extend vertically to the compression zone causing the total failure. Meanwhile, it is worthy to report that due to the weak bond at concrete-geogrid interface, all prism specimens were divided into individual segments joined with each other through the geogrid layers. It is obvious that, the trend of the P- $\Delta$ curves is similar for the three types of geogrids.

Fig. (6) shows the flexural behavior of prisms reinforced with uniaxial geogrids (U-1). It is clear that, the gained post cracking flexural strength increases with the increase in the number of geogrid layers. The prism reinforced with one layer of geogrid shows the largest deflection value. The flexural behavior of prism reinforced with two layers of geogrids shows two post peaks in the P- $\Delta$ curve. This is attributed to the tear of one or more rib or junction in the first layer of geogrids. Therefore, the second layer of the geogrid starts to absorb the flexural tensile stresses again. The percentages of post peak load to the first crack load are 76, 104 and 142 for prisms reinforced with U-1 geogrid of one layer, two layers and three layers, respectively.

Fig. (7) shows the flexural behavior of prisms reinforced with biaxial geogrids (BI-1). They show the same trend as the prisms reinforced with uniaxial geogrids. The gained post 
Mostafa Abd-Elmohsen, Flexural behavior of self-compacting concrete prisms reinforced ..........

cracking flexural strength is increasing by increasing the number of geogrid layers. The prism reinforced with three layers of geogrids shows the more ductile behavior than the prisms reinforced with one or two layers. It is observed that increasing the number of layers of the geogrids leads to an enhancement in the post peak behavior of prisms. The percentages of maximum post peak load to the first crack load are 52, 106 and 135 for prisms reinforced with BI-1 geogrid of one layer, two layers and three layers, respectively.

Fig. (8) shows the flexural behavior of prisms reinforced with biaxial geogrids (BI-2). This type of geogrids has no junctions between ribs and the geogrids is almost flat network. It also has some slight roughness in its surface which relatively improves its bond with concrete in the early stage of loading. This bond was weakened gradually in the post peak stage due to the absence of junctions and the very small thickness of the ribs. The obtained post cracking flexural strength does not significantly increase with the increase in the number of geogrid layers. The general trend of flexural behavior of prisms reinforced with two and three layers of geogrids is approximately the same. The percentages of postpeck load to the first crack load are 46, 80 and 82 for prisms reinforced with BI-2 geogrids of one layer, two layers and three layers, respectively.

The obtained results are matching with that presented by F. El Meski et al. [9], which reported that, using geogrid as reinforcement provides a ductile postcracking behavior, high fracture energy, high flexural strength, and large deflection values.

\section{Table 4.}

Flexural Test Results for Prisms

\begin{tabular}{|l|c|c|c|c|c|c|c|c|c|c|}
\hline Prism Results & PC & $\begin{array}{c}\text { U-1- } \\
1\end{array}$ & U-1-2 & U-1-3 & BI-1-1 & BI-1-2 & BI-1-3 & BI-2-1 & BI-2-2 & BI-2-3 \\
\hline $\begin{array}{l}\text { First crack load } \\
(\mathrm{kN})\end{array}$ & 16.65 & $\begin{array}{c}16.9 \\
6\end{array}$ & 18.23 & 15.18 & 15.11 & 12.73 & 14.09 & 18.99 & 18.49 & 18.30 \\
\hline $\begin{array}{l}\text { Post peak load } \\
(\mathrm{kN})\end{array}$ & --- & $\begin{array}{c}12.1 \\
1\end{array}$ & 19.04 & 21.56 & 7.86 & 13.52 & 18.81 & 9.86 & 14.82 & 15.02 \\
\hline max. Load (kN) & 16.65 & $\begin{array}{c}16.9 \\
6\end{array}$ & 19.04 & 21.56 & 15.11 & 13.52 & 18.81 & 18.99 & 18.49 & 18.49 \\
\hline min. Load (kN) & --- & 4.17 & 7.20 & 8.00 & 3.80 & 4.10 & 5.00 & 7.00 & 10.00 & 9.70 \\
\hline $\begin{array}{l}\text { max. Deflection } \\
\text { (mm) }\end{array}$ & 0.50 & 31.7 & 23.04 & 22.2 & 16.23 & 17.02 & 28.83 & 19.88 & 18.49 & 16.08 \\
\hline $\begin{array}{l}\text { Flexure } \\
\text { Strength (kPa) }\end{array}$ & 2220 & 2261 & 2539 & 2875 & 2015 & 1803 & 2508 & 2532 & 2465 & 2465 \\
\hline $\begin{array}{l}\text { Energy } \\
\text { (kN.mm) }\end{array}$ & 4.16 & 263 & 292 & 373 & 100 & 143 & 282 & 184 & 207 & 205 \\
\hline
\end{tabular}

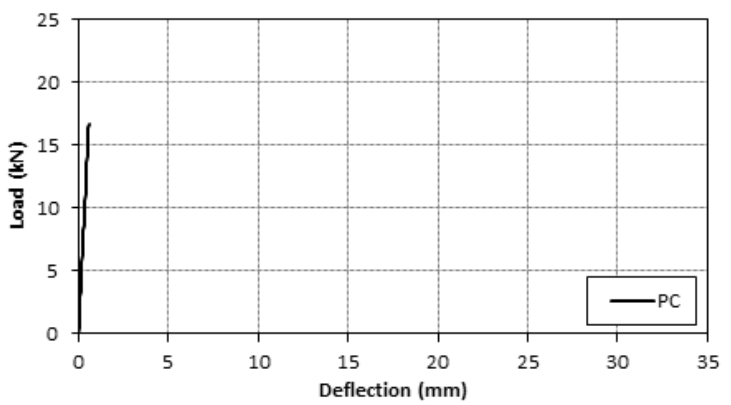

Fig. 5. Load-Deflection for PC Prism 


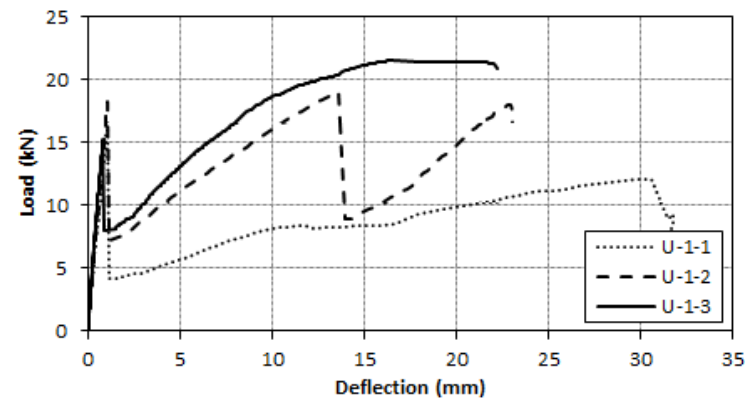

Fig. 6. Load-Deflection for Uniaxial Geogrid (U-1) Prisms

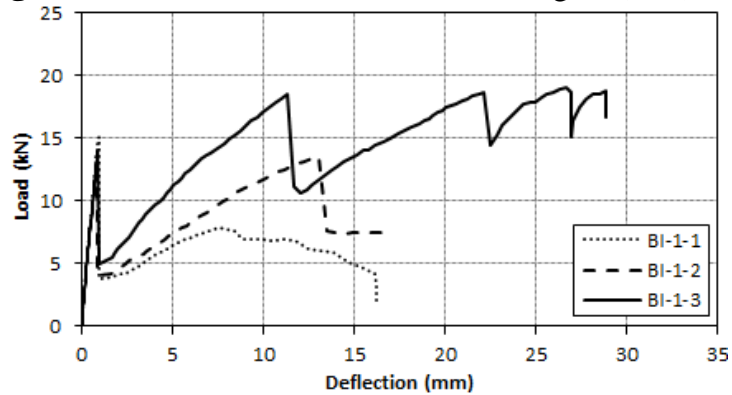

Fig. 7. Load-Deflection for Biaxial Geogrid (BI-1) Prisms

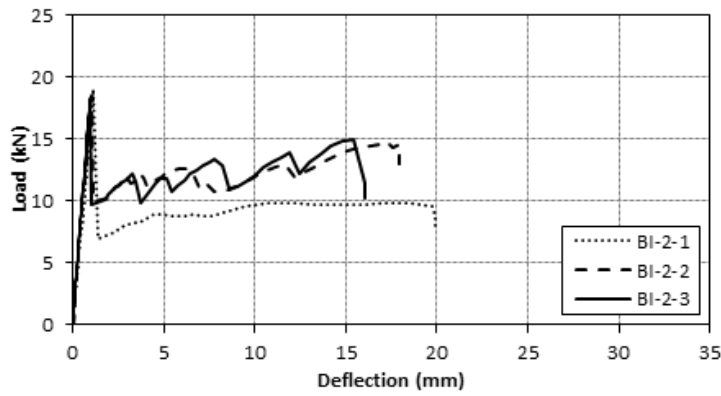

Fig. 8. Load-Deflection for Biaxial Geogrid (BI-2) Prisms

The effect of geogrid type on the flexural behavior of concrete prisms is shown in Fig. (9). It can be noticed that, the load capacity of BI-2 prisms is suddenly dropped to higher values than those of both U-1and BI-1 prisms as soon as the flexural crack occurred after reaching the concrete tensile strength. This is attributed to the relatively better bonding between this type and concrete in the early stage of loading.

Using one geogrid layer of type BI-2, for reinforcing concrete prism specimen, showed higher flexural strength than that of utilizing the other two geogrid types (U-1 and BI-1), as shown in Fig. 9-a. It also showed a relatively constant post crack flexural stresses until failure. Furthermore, U-1-1 specimen showed a gradually increase in the post crack flexural stresses and experienced the largest strain value at failure. However, BI-1-1 specimen showed the lowest flexural strength among the three types of geogrids.

The behavior of prisms reinforced with two geogrid layers, Fig. 9-b, showed that prisms U-1-2 and BI-1-2 behaved in a similar trend after the first crack was occurred. The flexural resistance was rebuilt again due to transferring tensile stress to the first geogrid layer. After reaching to the second peak of P- $\Delta$ curve, a sudden drop was occurred, which refers to transferring flexural stress to the second geogrid layer. This behavior is attributed to the weak 
Mostafa Abd-Elmohsen, Flexural behavior of self-compacting concrete prisms reinforced .........

bonding between concrete and geogrids. However, U-1-2 showed a better flexural behavior than BI-1-2. For BI-2-2 prism, the post cracking flexural behavior is almost constant until failure. This behavior is similar to that of BI-2-1, which is attributed to the relatively better bonding than that for the other two types, especially in the early stages.

The flexural behavior of prisms that were reinforced with three layers of geogrids, BI1-3 and BI-3-3, showed more than one peak in the post crack stage. However, the gained flexural strength of BI-1-3 was much bigger than that for BI-2-3 and its absorbed energy is about 1.38 times that of BI-2-3. The flexural behavior of U-1-3 was different from that for the other two types as the gained flexural strength after cracking was continuously increasing until a complete failure occurred.

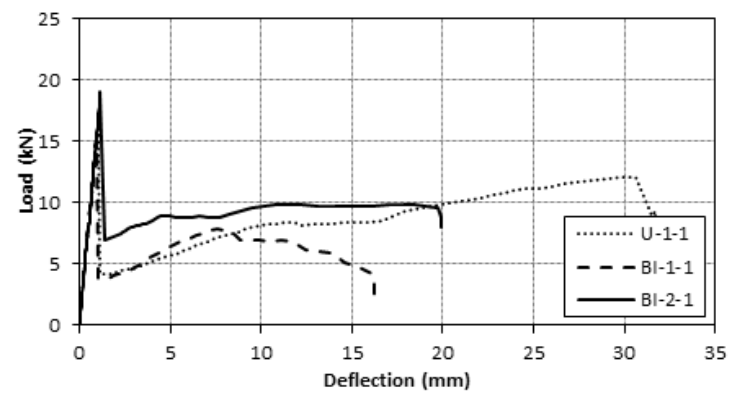

(a): 1-Layer

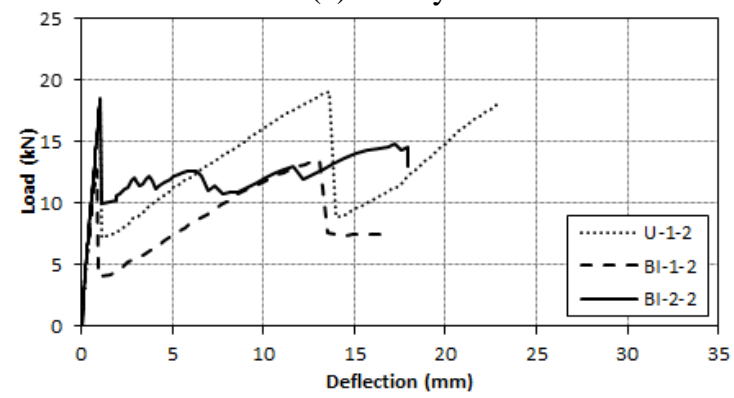

(b): 2-Layers

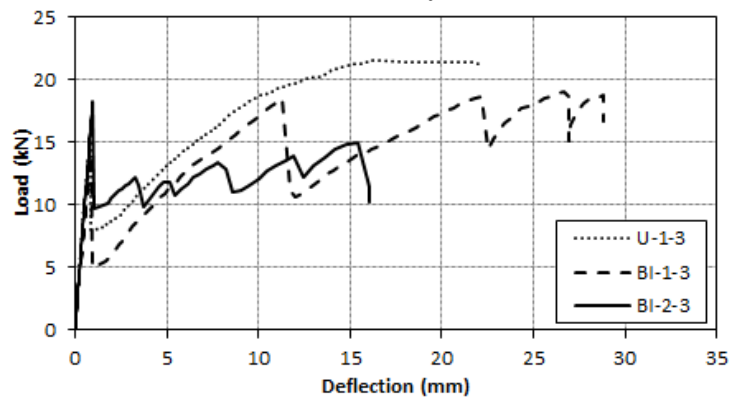

(c): 3-Layers

Fig. 9. Effect of Geogrid Type on Prism Load Deflection Behavior

\section{Energy absorption capacity}

Energy absorption capacity of each prism specimen is calculated from its load-deflection curve, Table (4). It is considered as the area under P- $\Delta$ curve. It is clear that the energy absorption capacity increases with increasing the number of geogrid layers for both prisms reinforced with uniaxial (U-1) and biaxial (BI-1) geogrid layer. The prisms with uniaxial 
geogrid (U-1) exhibited higher energy absorption capacity values than those of biaxial geogrids due to the large monitored ductility. For prisms reinforced with geogrid (U-1), the energy absorption capacity was increased by $11 \%$ and $42 \%$ for 2 and 3 geogrid reinforcement layers respectively with respect to one layer of geogrid reinforcement. Furthermore, for prisms reinforced with geogrid (BI-1), the energy absorption capacity was increased by $43 \%$ and $182 \%$ for 2 and 3 geogrid reinforcement layers respectively with respect to one layer of geogrid reinforcement. Finally, for prisms reinforced with biaxial geogrid (BI-2), the energy absorption capacity values were almost the same when using 2 or 3 layers of geogrids.

\section{Flexure strength}

Flexure strength is expressed as Modulus of Rupture R, and it is calculated according to ASTM C 78 using the following formula:

$$
R=\frac{P l}{b d^{2}}
$$

where $\mathrm{P}$ is the maximum total load measured in $\mathrm{kN} ; 1$ is the span length of $450 \mathrm{~mm}$; $\mathrm{b}$ is the specimen width of $150 \mathrm{~mm}$; and d is the specimen height of $150 \mathrm{~mm}$. The results were previously shown in Table (4).

It can be noticed that using uniaxial geogrid (U-1) for reinforcing prisms enhanced the flexural strength gradually by $1.86 \%, 14.35 \%$ and $29.49 \%$ when using one, two and three geogrid layers respectively. However, there is no obvious trend of enhancement for using both the two types of biaxial geogrids. Ii was observed that the prisms reinforced with BI-1 geogrids using one and two layers exhibited lower flexural strength than that of the PC prism.

\section{Proposed behavior}

Unexpectedly, a debonding failure was monitored for all geogrid prisms and it may be due to the smooth surface of the geogrid. Therefore, it is very important to make a correction to these actual trends through assuming no bond failure occurred. Based on the obtained load-deflection relationships, the optimum proposed behavior for all the investigated prisms reinforced with geogrid is plotted in Fig. (10) in comparison with their actual behaviors. The optimum proposed curves for all tested prism categorizes seem to be logic and reasonable for different number of geogrid layers. Therefore, a recommendation for getting a rough geogrid surface is necessary to enhance the bond strength at the geogrid-concrete interface surface. Results indicate also that the more number of the used geogrid layers, the more enhancement in flexural behavior, flexural strength, as well as ductility. However, the observed conflict as well as deviations monitored for the actual results arise mainly from the debonding failure occurred at the concrete-geogrid interface for all tested prisms. 


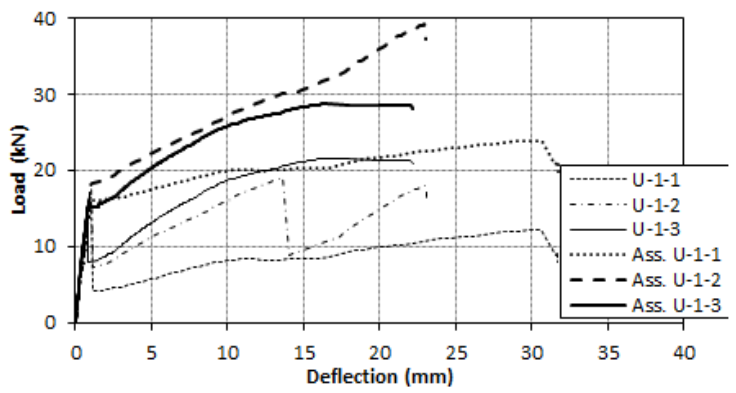

a- U-1 Prisms

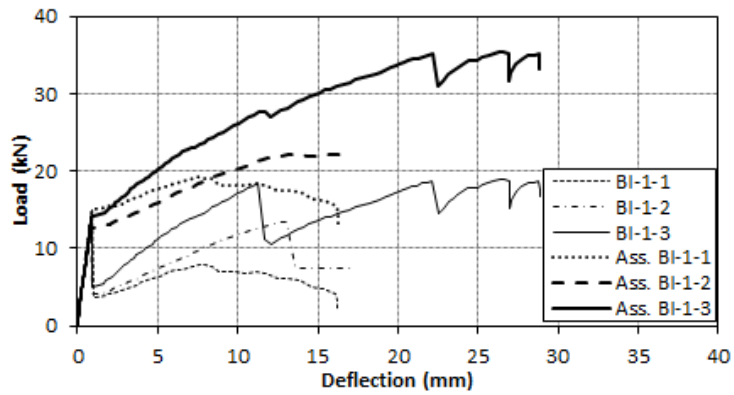

b- BI-1 Prisms

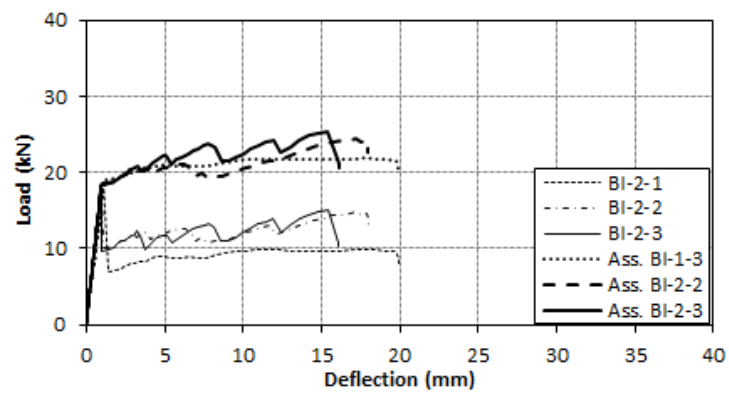

c- BI-2 Prisms

Fig. 10. Comparison between Optimum Proposed and Actual Behavior for Tested Prisms

\section{Failure mode of prisms}

The most frequent failure mechanism in $\mathrm{RC}$ beams due to bending stresses is a flexural failure. It is found from different studies, that the compression zone of the RC beam is safer from failure as the tension zone used to be under pure bending, due to properties of concrete. The critical area for beam under bending stresses is a tension zone of the RC beam [6]. Mostly, the failure initiated by the development of crack from tension zone, and extended up to compression zone before reaching to failure [12]. These cracks usually start from the bottom of applied load, which indicates flexural failure. Therefore, it is predicted that the application of geogrid in the tension zone of concrete prisms will enhance its flexure strength tremendously. However, applying only geogrid at the tension zone may cause de-bonding of the strip or premature failure as the cracks widen before reaching to ultimate load carrying capacity. The failure of RC prism reinforced with geogrid will occur due to various causes that involve concrete strength, area of geogrid (reinforcement ratio), etc. However, the most common failure modes reported in the previous studies [10] are as follows: 1) FRP rupture, 2) FRP and concrete cover separation, 3) FRP De-bonding, 4) 
Concrete Crushed at compression zone 5) Shear Crack, 6) Interfacial de-bonding at the concrete-geogrid interface and 7) De-bonding due to intermediate flexure-shear cracks. Shear failure is more devastating than flexural failure due to sudden failure. The flexural failure mode is still a more ductile mode than a shear failure mode.

As shown in Fig. (11), the tensile forces develop firstly at the bottom chord of the concrete in the tension zone and these have to be transferred to the internal bonded geogrid reinforcement layers. Consequently, a premature debonding failure is more likely rather than a flexural failure described above, which matches with the numerous previous experimental studies [10]. The failure mode of the prism occurred before reaching to its ultimate strength; most of the prisms lose their strength and durability as the load exceeds its capacity. A debonding failure mode has been observed in all tested prisms reinforced with geogrids, and this can be broadly classified into two types: (a) geogrid-concrete interface debonding failures which are associated with high interfacial stresses, and (b) debonding failures which are induced by a flexural or flexural-shear crack (intermediate crack). These debonding failure modes are unique to prisms reinforced with geogrids.

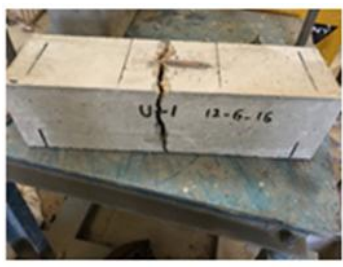

a- U-1-1

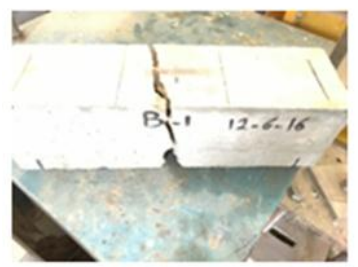

d- BI-1-1

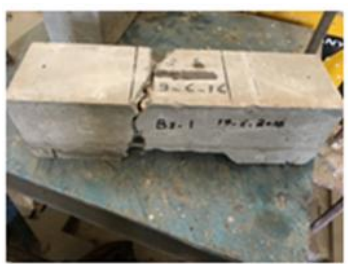

g- BI-2-1

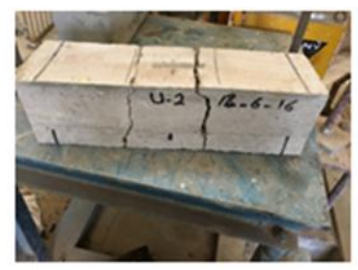

b- U-1-2

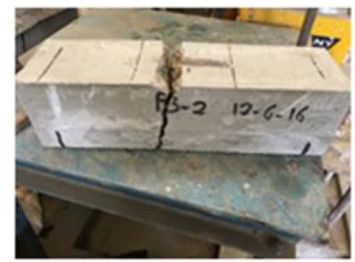

e- BI-1-2

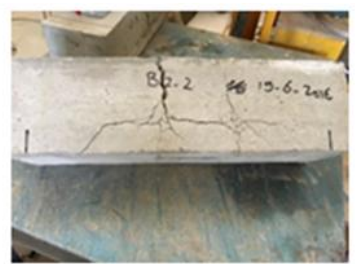

h- BI-2-2

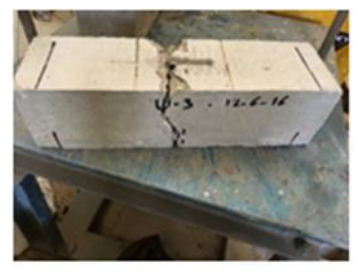

c- U-1-3

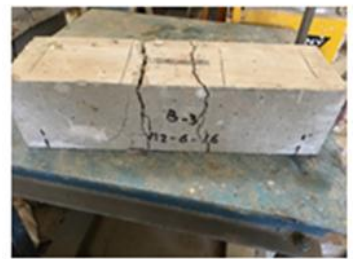

f- BI-1-3

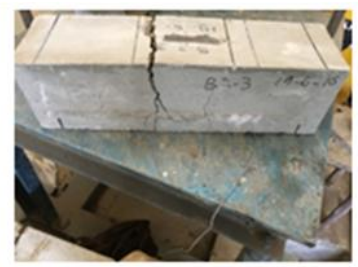

i- BI-2-3

Fig. 11. Crack Patterns and Failure Mode of Prisms Reinforced with Geogrid

\section{Conclusions}

This paper has presented an experimental investigation of flexural behavior of SCC prisms using uniaxial and biaxial geogrids as reinforcements with one, two and three layers. According to the results obtained in this study, the following conclusions can be drawn:

1- All types of geogrid reinforcement provide a ductile behavior in the post cracking stage, enhanced absorbed energy and large deformation values. 
Mostafa Abd-Elmohsen, Flexural behavior of self-compacting concrete prisms reinforced ..........

2- Uniaxial geogrid provides a better flexural behavior than biaxial geogrids. It significantly increases the absorbed energy and deformation values.

3- Using multi layers of geogrid reinforcement increase post crack flexure strength for uniaxial geogrid (U-1) and biaxial interlock geogrid (BI-1), however it was found not efficient with biaxial strap geogrid (BI-2).

4- Unexpectedly, a debonding failure is achieved, and it is induced by a flexural and / or flexural-shear crack (intermediate crack) to be the main failure mode of geogridconcrete prisms. This debonding failure mode is unique to prisms reinforced with geogrids due to the weakness of its bond.

\section{Recommendations}

Results obtained in this research showed the remarkable weakness of the bond strength at the concrete-geogrid interface that leads to the main failure reason of all the investigated geogrid prism specimens. Therefore, it is highly recommended to make some surface treatments for geogrid layers for the aid of bond strength enhancement and investigate the effect of applying small pre-stressing force to geogrids on the flexure behavior of concrete prisms. Using geogrids as reinforcements for canal lining, slabs on grade also needs to be investigated as well as compared with that reinforced with both FRP and steel. It is also recommended to investigate the effect of geogrid modulus of elasticity on the flexural behavior of structural members.

\section{Acknowledgement}

The author wishes to acknowledge Prof. Eehab A. Khalil for his sincere support and revision. The author also gratefully appreciates the technical support and effort made by Prof. Mohamed I. Abo-Khashaba to complete this research in its final form.

\section{REFERENCES}

[1] Al-Qadi, I. L., Brandon, T. L., and Bhutta, A. (1997). "Geosynthetic Stabilized Flexible Pavements," Proceedings of Geosynthetics '97, IFAI, Vol. 2, Long Beach, California, pp. 647-662.

[2] ASTM. (2009). "Standard Test Method for Determining Tensile Properties of Geogrids by the Single or Multi-Rib Tensile Method1". D6337-01.

[3] ASTM. (2009). "Standard test method for flexural strength of concrete (using simple prism with third-point loading)." C78-09.

[4] Barksdale, R. D., Brown, S. F., and Chan, F. (1989). "Potential Benefits of Geosynthetics in Flexible Pavement Systems," National Cooperative Highway Research Program Report No. 315, Transportation Research Board, National Research Council, Washington, D.C.

[5] Berg, R. R., Christopher, B. R., and Perkins, S. (2000). "Geosynthetic Reinforcement of the Aggregate Base/Subbase Courses of Pavement Structures," Geosynthetic Materials Association White Paper II, Geosynthetic Materials Association, Roseville, Minnesota.

[6] Bulavs, F. Radinsh,I. and Tirans,N. (2005), "Improvement of capacity in bending by the use of FRP layers on RC beams," Journal of civil engineering and management, vol. 11, pp. 169-174.

[7] Cancelli, A., Montanelli, F., Rimoldi, P., and Zhao, A. (1996). "Full Scale Laboratory Testing on Geosynthetics Reinforced Paved Roads," Proceedings of the International Symposium on Earth Reinforcement, Fukuoka, Kyushu, Japan, pp. 573-578.

[8] Collin, J. G., Kinney, T. C., and Fu, X. (1996). "Full Scale Highway Load Test of Flexible Pavement Systems with Geogrid Reinforced Base Courses," Geosynthetics International, Vol. 3, No. 4, pp. 537-549. 
[9] F. El Meski, G. R. Chehab. (2014). "Flexural Behavior of Concrete Beams Reinforced with Different Types of Geogrids," Journal of Materials in Civil Engineering, ASCE, ISSN 0899-1561/04014038(8).

[10] Imran, M., Shafiq, N., and Akbar, I. (2013). "Strengthening Techniques \& Failure Modes of RC Beam Strengthened Using Fibre Reinforced Polymer. A Review", International Journal of Engineering Technology (JET) Vol.2 No.2, August 2013, 93-98.

[11] Koerner, Robert M. (1998). Designing With Geosynthetics. Fourth Edition, Prentice Hall, Upper Saddle River, New Jersey.

[12] Marco Di Ludovico, A. N. Andrea Prota, and Edoardo Cosenza, (2005),"Repair of Bridge Girders with Composites: Experimental and Analytical Validation," ACI Structural Journal.

[13] Maxwell, S., Kim,W., Edil, T. B., and Benson, C. H. (2005). "Effectiveness of geosynthetics in stabilizing soft subgrades." Final Rep. No. 0092-45-15, Dept. of Civil and Environmental Engineering, Univ. of Wisconsin-Madison, Madison, WI.

[14] Miura, N., Sakai, A., Taesiri, Y., Yamanouchi, T., and Yasuhara, K. (1990). "Polymer Grid Reinforced Pavement on Soft Clay Grounds," Geotextiles and Geomembranes, Vol. 9, No. 1, pp. 99-123.

[15] Perkins, S. W. and Ismeik, M. (1997a). "A Synthesis and Evaluation of Geosynthetic Reinforced Base Layers in Flexible Pavements: Part I," Geosynthetics International, Vol. 4, No. 6, pp. 549-604.

[16] Santoni, Rosa L., Smith, Carroll J., Tingle, J.S., and Webster , S.L. (2001). "Expedient Road Construction Over Soft Soils," Technical Report TR-01-7, U.S. Army Engineer Research and Development Center, Waterways Experiment Station, Vicksburg, MS.

[17] Tang, X., Chehab, G. R., and Kim, S. (2008a). "Laboratory study of geogrid reinforcement in Portland cement concrete." 6th RILEM Conf. on Cracking in Pavements, Pavement Cracking Mechanisms, Modeling, Detection, Testing, and Case Histories, RILEM, Taylor and Francis Group, London, 769-778.

[18] Webster, S. L. (1993). "Geogrid Reinforced Base Courses for Flexible Pavements for Light Aircraft: Test Section Construction, Behavior Under Traffic, Laboratory Tests, and Design Criteria," Technical Report GL-93-6, U.S. Army Engineer Waterways Experiment Station, Vicksburg, MS. 


\section{السلوك الإحنائى للكمرات الخرسانية ذاتية الدمك المسلحة بالثبكات البوليمرية}

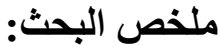

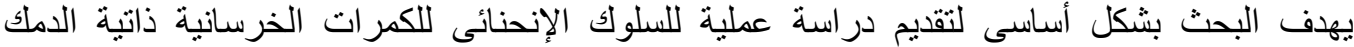

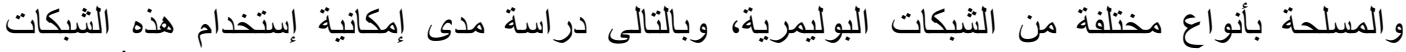

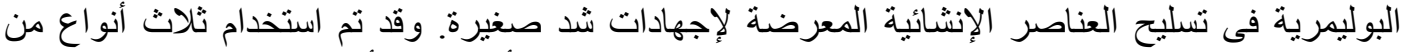

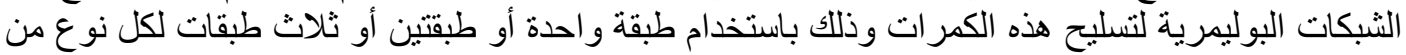

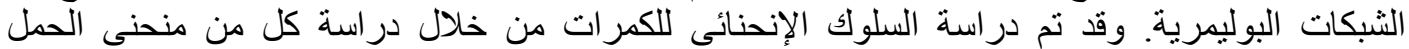

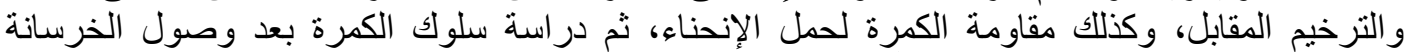

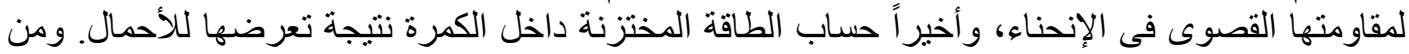

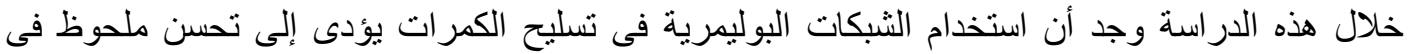

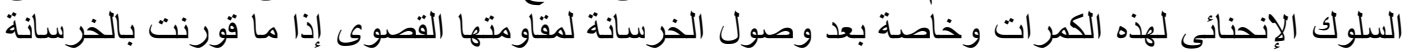

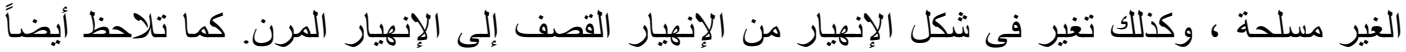

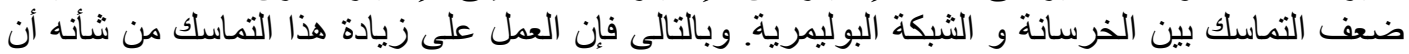
يحسن بشكل كبير من خو اص الخرسانة فى الإنحناء. 